detected at a rate of $7 / 1000$. In other words, this is a form of self-selection into a screening programme because of nondescript symptoms, as is occurring now with the cervical cancer screening programme.

The second point is that reliance on the eye alone at endoscopy is not sufficient. For example, real advances in the understanding of early carcinoma of the cervix and precancer were made only after large numbers of "normal-looking" cervices were subjected to cytological examination.

As it is obvious that we are unable to indulge in mass screening for the diagnosis of these early cancers, then whenever an individual in one of the high-risk groups above is gastroscoped (perhaps for symptoms unrelated to the stomach) let there at least be a more systematic taking of brush and biopsy material, and even simple wash specimens. Only in this way will a greater number of "early" gastric cancers be found, and this should serve to improve what is at the present moment a very bad state of affairs.

O A N Husain JOHN M GRAINGER

Charing Cross and

St Stephen's Hospitals
London Kasugai, T, and Kobayashi, S, American fournal of
Gastroenterology, 1974,62, 199 .

Husein, O A N, Proceedings of the Royal Society of Medicine, 1976, 69, 489.

\section{Heat wave deaths and drugs affecting temperature regulation}

SIR,-I have been asked to comment on the death from heatstroke during the recent heat wave of a man aged 32 years who suffered from congenital diplegia. The maximum shade temperature $\left(33.1^{\circ} \mathrm{C}\left(91.6^{\circ} \mathrm{F}\right)\right)$ that day was the highest recorded at the local weather station in 52 years, but although some patients had raised body temperatures there were no other serious cases of acute heat illness in the hospital where he lived.

$\mathrm{He}$ was an obese young man $(17 \mathrm{~kg}$ above the average for his age and height) but he had not been exerting himself unduly and was wearing only a vest and T-shirt. A nurse noticed that he looked unwell after watching television following his midday meal and called the duty physician, who arrived within 5-10 minutes. By this time the patient was nearly unconscious, his temperature was $41.7^{\circ}\left(107^{\circ} \mathrm{F}\right)$, and he was not sweating. Despit cold and ice-water sponging and the use of fan his body temperature could not be reduced below $40^{\circ} \mathrm{C}\left(104^{\circ} \mathrm{F}\right)$ and he died six hours later withou regaining consciousness. The findings at necropsy were consistent with death from heat stroke. During the week before his death he had been his usual self and enjoyed his normal pattern of health. The most significant factor in the history was that he had been taking chlorpromazine fo two years and was receiving $75 \mathrm{mg}$ three times a day. The last dose was taken about $1 \frac{1}{4}$ hours before he became acutely ill.

The phenothiazines are known to interfere with thermoregulation (British National Formulary 1976-78) and to suppress sweating. Exton-Smith ${ }^{1}$ has warned physicians through your columns that the dosage of phenothiazines, especially in elderly patients, should be reduced or discontinued in periods of very cold weather and when heating facilities are in short supply. It is less well recognised in Britain that there may be a similar hazard when the ambient temperatures are abnormally high and cooling facilities are hard to lay on at short notice. Zelman and Guillan² reported three deaths from hyperthermia in patients receiving relatively large dosages of chlorpromazine (450-500 mg daily) during a heat wave at Topeka, Kansas, in 1969 and Mahrer et $\mathrm{al}^{3}$ reported mepazine-induced hyperthermia in a man who ceased to sweat during a heat wave in New York City when the ambient temperature was $32 \cdot 2^{\circ} \mathrm{C}\left(90^{\circ} \mathrm{F}\right)$ but who recovered in eight hours with wetted bed sheets and the use of a fan. Cares et al measured the rectal temperatures of 3014 patients receiving chlorpromazine (" $90^{\circ}$, average" $200-400 \mathrm{mg}$ daily) at Kings Park State Hospital, New York, during an 18month period and reported "fever" in $0.8^{\circ}$ o of cases. Thus individual variability is almost certainly very considerable and it is only the occasional person who may be at risk from hyperthermia and cannot be readily identified.

It is of importance to establish whether any of the excess deaths reported by the Office of Population Censuses and Surveys during the early weeks of the recent heat wave were deaths of persons on large dosages of phenothiazines, atropine-like preparations, barbiturates, or other drugs which might impair thermoregulation or depress sweat gland activity. I would be most grateful if physicians who have had cases of heat stroke or hyperthermia, fatal or otherwise, among patients being treated with such drugs during hot weather would send me a report to the address shown below.

Frank Ellis

MRC Environmental Physiology Unit,

ondon School of Hygiene

and Tropical Medici

Keppel Street (Gower Street)

London WC1E 7HT

${ }^{1}$ Exton-Smith, A N, British Medical fournal, 1972, 1 , 44

Zelman, S, and Guillan, $\mathrm{R}$, American fournal of Psychiatry, 1970, 126, 1787.
.

Mahrer, P R, Bergman, P S, and Estren, S, American fournal of Psychiatry, 1958, 115, 337

1957, 114, 318. al, American fournal of Psychiatry

\section{Thyrotoxic vomiting}

SIR,-We were interested to read the report on thyrotoxic vomiting by $\mathrm{Dr} F \mathrm{D}$ Rosentha and others (24 July, p 209). Although it seems likely that the vomiting was, in most of them, attributable to thyrotoxicosis, in the cases described there were several complicating factors. As mentioned, case 2 may have had Addison's disease and the data presented did not rule out inadequate substitution therapy as a cause of the vomiting. In addition there is no mention of gastrointestinal investigations in six of the seven patients. We have recently seen two hyperthyroid patients presenting with gastrointestinal symptoms including vomiting, whom we wish to report on.

Case 1

A 68-year-old woman was admitted as an emergency with a six-week history of palpitations, nausea, anorexia, and vomiting and postprandia epigastric pain. She had lost $13 \mathrm{~kg}$ in weight. There was no history of diarrhoea.

On examination she had atrial fibrillation with ventricular rate of $120 / \mathrm{min}$ but was clinically euthyroid. The Wayne scale score was 6 , which is in the euthyroid range. Investigations showed urea of 8 , sodium 136 , potassium $2 \cdot 9$, bicarbonate
34 , and calcium $2 \cdot 20 \mathrm{mmol} / 1$, respectively. The free thyroxine index was 226 (normal range $60-150$ ), and the $\mathrm{TSH}$ response to thyrotrophin releasing hormone was flat. Barium swallow and meal were normal.

She was treated with digoxin and potassium supplements. Electrolyte balance returned to normal and her atrial fibrillation was easily controlled, but her symptoms persisted. Subsequen treatment with $5 \mathrm{mC}$ iodine-131 resulted in complete relief of all her gastrointestinal symptoms by one month. She remains well three months after treatment.

Case 2

A 42-year-old Iranian woman presented with a two-year history of anorexia, nausea, and vomiting generalised postprandial abdominal pain, and diarrhoea. She had lost $12 \mathrm{~kg}$ in weight. Numerous investigations in Iran proved normal.

On examination she had a diffuse goitre with soft bruit and mild proptosis but no other thyrotoxic features. Her Wayne scale score was 4 Investigations, including urea, electrolytes, liver function tests, blood count, stool cultures, barium meal and follow-through, were normal. Serum thyroxine was $249 \mathrm{nmol} / 1$ (normal range 70-160). She was started on treatment with propranolo with rapid relief of her symptoms.

We feel that these two cases in addition to Dr Rosenthal and colleagues' confirm the clinical entity of thyrotoxic vomiting. Moreover, the spectrum of mode of presentation is well illustrated in that one was admitted as an emergency and the other eluded diagnosis for two years. Both our patients had abdomina pain as did case 1 of Dr Rosenthal and others, and our first case did not have diarrhoea. Despite the association we feel that all patients with abdominal symptoms and thyrotoxicosis should have gastrointestinal investigations

A J IssaACS R D G LESLIE

Westminster Hospital,

London W1

SIR,-In their account of thyrotoxic vomiting (24 July, p 209) Dr F D Rosenthal and others state that this presentation is not always a sign of impending crisis. They do not mention another possible and equally dangerous complication-Wernicke's encephalopathy. This was illustrated by the following case.

A 64-year-old woman was under surgical investigation for loss of weight and vomiting when she lapsed into semicoma. She was afebrile, with a persistent tachycardia. She had small pupils, bilateral ptosis, and almost total loss of passive conjugate gaze (doll's head movements). Limbs were moved freely, but tendon reflexes were absent, right plantar response flexor, and left, plantar extensor. Two separate estimations of blood pyruvate showed raised levels, 284 and $330 \mu \mathrm{mol} / 1$ (normal $45-80 \mu \mathrm{mol} / 1$ ), and the EEG showed generalised slow activity at theta and delta frequencies. The cerebrospinal fluid was normal.

Within $\mathbf{7 2}$ hours of starting intravenous thiamin her level of consciousness had improved but return to a fully rational state was delayed. At follow-up 16 months later she had persistent amnesia for he first month in hospital and retrograde amnesia for two months before her admission. On the 17th hospital day she developed atrial fibrillation and on the 19th day the radioactive iodine test was reported abnormal with $78 \%$ uptake at 24 hours and $70 \%$ at 48 hours. The protein bound iodine-131 was $1.3 \%$ of the dose $(5 \mu \mathrm{Ci})$ per litre of plasma. Her thyroid gland was not palpable and no thyroid shadow was visible on $x$-rays of chest and neck.

During her subsequent treatment with carbimazole in the medical unit at Cardiff Royal Infirmary she developed a goitre, over 